\title{
Endogenous Regulation of Serotonin Release in the Hamster Suprachiasmatic Nucleus
}

\author{
Thomas E. Dudley, Lisa A. DiNardo, and J. David Glass \\ Department of Biological Sciences, Kent State University, Kent, Ohio 44242-0001
}

Serotonin (5-HT) has been strongly implicated in the regulation of the mammalian circadian clock located in the suprachiasmatic nuclei (SCN). However, little is known of the pattern of neuronal 5-HT release in the SCN or of the factors involved in regulating its release. Using in vivo microdialysis, we demonstrated the existence of a daily rhythm in the output of 5-HT in the SCN of freely behaving hamsters. This rhythm was characterized by a sharp increase in release from a nadir during late midday to peak levels at the light/dark transition. Output declined to basal levels throughout the remainder of the night. A similar pattern also was evident under constant darkness, with increased 5-HT output occurring at the onset of subjective night. Locomotor activity induced by exposure to a novel running wheel had a pronounced phase-dependent effect on 5-HT release in the SCN, with stimulation during the light phase and suppression during the late dark phase. Systemic application of the somatodendritic 5- $\mathrm{HT}_{1 \mathrm{~A}}$ agonist BMY 7378 had a significantly greater suppressive effect on $5-\mathrm{HT}$ release in the SCN during the late dark phase compared with mid light phase, indicating that a variation in raphe autoreceptor response may underlie the time-dependent effects of wheel running on 5-HT release. Collectively, these results show that the daily rhythm in output of 5-HT in the SCN is generated endogenously, and that behavioral state can strongly influence serotonergic activity in the circadian clock in a phase-dependent manner.

Key words: serotonin; suprachiasmatic nuclei; hamster; circadian rhythm; microdialysis; 5-HT ${ }_{1 A}$ receptor
The suprachiasmatic nuclei (SCN) represent the major center for the generation and regulation of mammalian circadian rhythms (Rusak and Zucker, 1979; Moore, 1983; Klein et al., 1991). Circadian rhythms are synchronized to the daily light/dark cycle principally by photic information relayed from the retina to the SCN. This process is mediated by retinal input supplied to the SCN directly by the retinohypothalamic tract (Hendrikson et al., 1972; Moore and Lenn, 1972; Pickard, 1982; Youngstrom and Nunez, 1986; Johnson et al., 1988) and indirectly via the geniculohypothalamic tract (Card and Moore, 1982; Johnson et al., 1989), which also is thought to convey nonphotic entraining input to the SCN (Rusak et al., 1989; Biello et al., 1994; Janik and Mrosovsky, 1994; Janik et al., 1995). A third major input to the $\mathrm{SCN}$ is a serotonergic projection from the raphe nuclei that terminates primarily in the retinorecipient region of the nucleus (Azmitia and Segal, 1978; Moore et al., 1978; Meyer-Bernstein and Morin, 1996).

Serotonin (5-HT) has been implicated in the modulation of photic signaling in the SCN and the resetting of circadian phase. Serotonergic agonists inhibit photically related SCN responses, including light-induced phase shifts in free-running locomotor activity (Rea et al., 1994; Pickard et al., 1996), light-induced Fos protein immunoreactivity in SCN cells (Selim et al., 1993; Glass et al., 1994, 1995), electrical activity of light-responsive SCN cells (Miller and Fuller, 1990; Ying and Rusak, 1994, 1997), and SCN field potentials evoked by electrical stimulation of the optic nerve (Rea et al., 1994). These agonists also have pronounced phase-

\footnotetext{
Received Nov. 17, 1997; revised April 10, 1998; accepted April 13, 1998.

This work was supported by National Institutes of Health Grant NS35229 to J.D.G. We are grateful to Greg Grossman and Jon Roberts for their technical assistance.

Correspondence should be addressed to J. David Glass, Department of Biological Sciences, Kent State University, Kent, OH 44242-0001.

Copyright (C) 1998 Society for Neuroscience $\quad 0270-6474 / 98 / 185045-08 \$ 05.00 / 0$
}

shifting effects on the circadian locomotor activity rhythm (Tominaga et al., 1992; Edgar et al., 1993; Bobrzynska et al., 1996a; Mintz et al., 1997) and on the circadian rhythm of neuronal activity measured from SCN slices (Prosser et al., 1990, 1993; Medanic and Gillette, 1992; Shibata et al., 1992). Consonant with these findings are reports that endocrine and behavioral circadian rhythms are significantly affected by manipulating brain 5-HT levels (Honma et al., 1979; Szafarczyk et al., 1981; Levine et al., 1986; Banky et al., 1988; Duncan et al., 1988; Smale et al., 1990; Morin and Blanchard, 1991a,b).

In contrast to the well-characterized effects of 5-HT agonists in the circadian system, little is known concerning the regulation of endogenous 5-HT release in the SCN. There are reports of daily variations in indices of serotonergic activity in the SCN, including $\left[{ }^{3} \mathrm{H}\right] 5-\mathrm{HT}$ uptake (Meyer and Quay, 1976), neuronal sensitivity to 5-HT (Mason, 1986), imipramine binding to 5-HT reuptake sites (Wirz-Justice et al., 1983), tissue 5-HT content (Hery et al., 1982; Cagampang and Inouye, 1994), and extracellular concentrations of the 5-HT metabolite 5-hydroxyindoleacetic acid (5-HIAA), (Faradji et al., 1983; Ramirez et al., 1987; Glass et al., 1992, 1993). However, because these parameters are not accurate indicators of synaptic 5-HT release per se, the nature of daily neuronal 5-HT output in the SCN remains speculative. It is also unclear whether the putative daily rhythm in 5-HT output in the SCN is driven by internal pacemakers or by environmental influences. The aim of the present study, therefore, was to characterize the daily profile of in vivo neuronal 5-HT release in the $\mathrm{SCN}$ region of freely behaving hamsters using brain microdialysis. We also used this methodology to evaluate the influences of light and locomotor activity on 5-HT release in the SCN to provide fundamental information on factors regulating serotonergic activity in the circadian clock. 


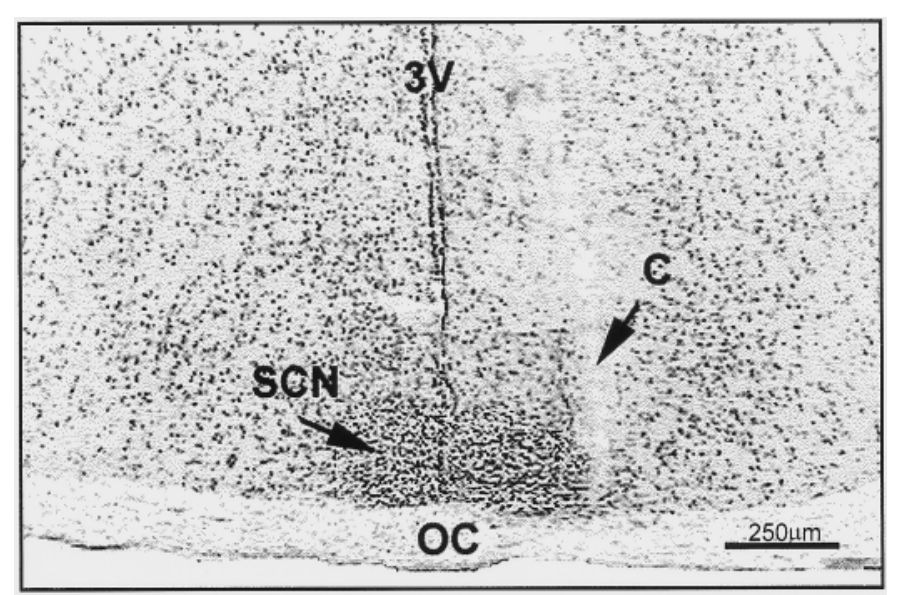

Figure 1. Representative coronal section through the midposterior aspect of the SCN showing a microdialysis cannula tract $(C)$ at the lateral margin of the nucleus. Section is stained with cresyl violet. $3 \mathrm{~V}$, Third ventricle; $O C$, optic chiasm.

\section{MATERIALS AND METHODS}

\section{Animals}

Adult male Syrian hamsters (Mesocricetus auratus) raised from breeder pairs obtained from Harlan Sprague Dawley (Madison, IL) were used for experimentation. The animals were maintained in a temperaturecontrolled $\left(22^{\circ} \mathrm{C}\right)$ vivarium under a $14 / 10 \mathrm{hr}$ light/dark photocycle $(200$ lux illuminance; lights on at 7:00 A.M.) and were provided food and water ad libitum.

\section{Microdialysis-HPLC}

The microdialysis-HPLC procedures developed in this laboratory for measuring 5-HT release in the SCN of Syrian hamsters have been described previously (Glass et al., 1995). Under sodium pentobarbital anesthesia (Nembutal, $50 \mathrm{mg} / \mathrm{kg}$ ), the animals received a microdialysis probe stereotaxically aimed at the lateral margin of the midposterior aspect of the rostrocaudal axis of the SCN, which contains the largest concentration of serotonergic fibers and terminals (Fig. 1) (MeyerBernstein and Morin, 1996) (anterior-posterior, $0.0 \mathrm{~mm}$ from bregma; lateral, $0.3 \mathrm{~mm}$ from midline; horizontal, $-8.0 \mathrm{~mm}$ from dura, with head level). Microdialysis was undertaken the following day. The microdialysis probes were constructed from hemicellulose dialysis tubing with $12 \mathrm{kDa}$ cutoff (230 $\mu \mathrm{m}$ OD; Spectra-por, Fisher Scientific, Pittsburgh, PA) glued to a 26 gauge stainless steel outer cannula containing a fused silica inner cannula (Polymicro Technologies, Phoenix, AZ). The dialyzing tip length of the probes was $1.0 \mathrm{~mm}$. In an experiment designed to examine the extent of contamination of SCN microdialysates with 5-HT from outside the SCN, the dialysis tips were occluded with epoxy, except for a small window of active membrane $(\sim 200 \times 300 \mu \mathrm{m})$ aimed medially at the SCN. In all experiments, probes were perfused with artificial CSF (ACSF), (in mm: $147.2 \mathrm{NaCl}, 4.0 \mathrm{KCl}$, and $1.8 \mathrm{CaCl}_{2}, \mathrm{pH} 7.2$ ) at flow rates of 1.2 or $1.8 \mu \mathrm{l} / \mathrm{min}$. Probe position was verified histologically from $20-\mu \mathrm{m}$-thick frozen sections stained with cresyl violet at the end of the experiment.

Microdialysates were analyzed for 5-HT using a high-performance liquid chromatograph with an amperometric radial flow electrochemical detector [Bioanalytical Systems (BAS), West Lafayette, IN]. The detector was set at a potential of $590 \mathrm{mV}$ relative to an $\mathrm{AgCl}$ reference cell. A $20 \mu \mathrm{l}$ aliquot of microdialysate was injected directly onto a $1.0 \times 100 \mathrm{~mm}$ reverse-phase $3 \mu \mathrm{m} \mathrm{C}-18$ column (BAS). Mobile phase consisted of $9.45 \mathrm{gm}$ of monochloroacetic acid, $3.6 \mathrm{gm}$ of $\mathrm{NaOH}, 0.25$ $\mathrm{gm}$ of $\mathrm{Na}_{2}$ EDTA, and $0.2 \mathrm{gm}$ of octane sulfonic acid in 1.01 of purified distilled water, $\mathrm{pH} 3.1$. Tetrahydrof uran $(6 \mathrm{ml})$ was added after filtration. Flow rate through the column was $90 \mu \mathrm{l} / \mathrm{min}$, and sensitivity (the minimal amount of 5-HT producing a signal four times that of background) was $\sim 500 \mathrm{fg}$ (average baseline content of 5 -HT in a $20 \mu \mathrm{l}$ sample of SCN microdialysate ranged between 5 and $10 \mathrm{pg}$ ). The 5-HT reuptake inhibitor citalopram $(4.0 \mu \mathrm{M}$; Farmitalia, Milano, Italy), was added to the ACSF perfusate in all experiments. Authenticity of the 5 -HT peak was verified by (1) coelution with authentic standard, (2) increases after electrical stimulation of the median raphe (Dudley and Glass, 1996) or localized perfusion with ACSF containing citalopram or $100 \mathrm{~mm} \mathrm{KCl}$, and (3) decreases after localized perfusion with $\mathrm{Ca}^{2+}$-free ACSF or systemic treatment with the 5 - $\mathrm{HT}_{1 \mathrm{~A}}$ receptor agonist 2-dipropylamino-8-hydroxy-1,2,3,4-tetrahydro-naphthalene hydrobromide (8-OH-DPAT; Research Biochemicals, Natick, MA) or raphe 5-HT $\mathrm{HA}_{1 \mathrm{~A}}$ mixed autoreceptor agonist BMY 7378 (Research Biochemicals).

\section{Experimental protocol}

Daily profiles of 5-HT release. Microdialysis was undertaken in separate groups of animals maintained under light/dark (LD) $(n=12)$ or constant darkness [dark/dark (DD); $n=6$ ]. After a $2 \mathrm{hr}$ equilibration period, samples were collected continuously at hourly intervals over $24 \mathrm{hr}$. In a separate experiment, microdialysis also was performed over $48 \mathrm{hr}$ under LD to confirm a repeating daily cycle of 5 -HT output $(n=5)$. For the LD groups, sample collection began at $1400 \mathrm{hr}$ [zeitgeber time (ZT) 6, with ZT 12 being the time of lights off]. For the DD group, sample collection began between circadian times (CTs) $1-6$, with CT 12 designated as the onset of subjective night (onset of nocturnal locomotor activity). Microdialysis under dark conditions was undertaken in the absence of visible light using infrared goggles. For animals under DD, microdialysis was initiated after at least a 2 week period of exposure to this condition. Stereotaxic implantation of dialysis probes in the DD group was undertaken by anesthetizing the animals in the dark and preventing exposure of their eyes to light during surgery using a light-proof shield. The phase of the circadian activity rhythm of animals under DD was determined from actograms of the animals' locomotor behavior monitored continuously using a computerized system running Dataquest III data acquisition software (Minimitter, Sunriver, OR). The onset of activity (CT 12) was defined as the first 6 min interval that was preceded by at least a $6 \mathrm{hr}$ period of inactivity and was followed by a period of at least $30 \mathrm{~min}$ of sustained activity.

Wheel-running-induced 5-HT release. The day after probe implantation, microdialysis was initiated with a $2 \mathrm{hr}$ equilibration period followed by 1 $\mathrm{hr}$ of baseline collection in the home cage, collection during confinement to a 14 inch running wheel (Ancare, Bellmore, NY) for $3 \mathrm{hr}$, and transfer back to the home cage for a $1 \mathrm{hr}$ postrun collection period. The sampling interval was $20 \mathrm{~min}$. This procedure was performed in four separate groups of animals under LD, with wheel-running commencing at ZTs 1, 4 , 9, and 19 ( $n=5-8$ per group). Microdialysis of the ZT 19 group was conducted in complete darkness. A magnetic switch attached to the wheel interfaced with a Dataquest III system was used to count wheel revolutions in $20 \mathrm{~min}$ batches corresponding to each microdialysis sample.

Verification of neuronal 5-HT release. Pharmacological agents were used to verify the authenticity of the 5-HT peak from chromatographed SCN microdialysates and to verify the neuronal origin of the 5-HT. These manipulations included localized perfusions via the microdialysis probe with ACSF containing $100 \mathrm{~mm} \mathrm{KCl}(n=4), \mathrm{Ca}^{2+}$-free ACSF with 0.2 mM EDTA $(n=5)$ and systemic application of 8 -OH-DPAT $(5 \mathrm{mg} / \mathrm{kg}$; $n=5$ ). For all treatments, probes were equilibrated for $2 \mathrm{hr}$, and $1 \mathrm{hr}$ of baseline samples were subsequently collected before treatment. A liquid switch with negligible dead space was used to change between normal ACSF and the high- $\mathrm{K}^{+}$or $\mathrm{Ca}^{2+}$-free solutions. For all treatments, sample collection interval was $20 \mathrm{~min}$, and sampling was continued for 3 hr after treatment onset at ZT 4. A further experiment was performed using intraperitoneal injection of the mixed 5- $\mathrm{HT}_{1 \mathrm{~A}}$ autoreceptor agonist BMY 7378 at ZT $6(n=5)$ and ZT $19(n=5)$ and saline controls $(n=$ 3 ) to examine time-of-day differences in 5-HT autoreceptor-mediated suppression of SCN 5-HT output.

Statistics. Data from the wheel-running and pharmacological experiments were converted to percentage of the mean of the three pretreatment baseline collections ( $1 \mathrm{hr}$ ) and were analyzed using a one-way ANOVA. Treatment effects were determined using the Student-Newman-Keuls test. Individual 24 or $48 \mathrm{hr}$ profiles of 5-HT release were normalized by expressing values as a percentage of the daily mean. Differences between nighttime means and the averaged daytime mean were determined using Dunnet's test procedure for comparing multiple group means (Zar, 1983). For all analyses, the level of significance was set at $p<0.05$. 

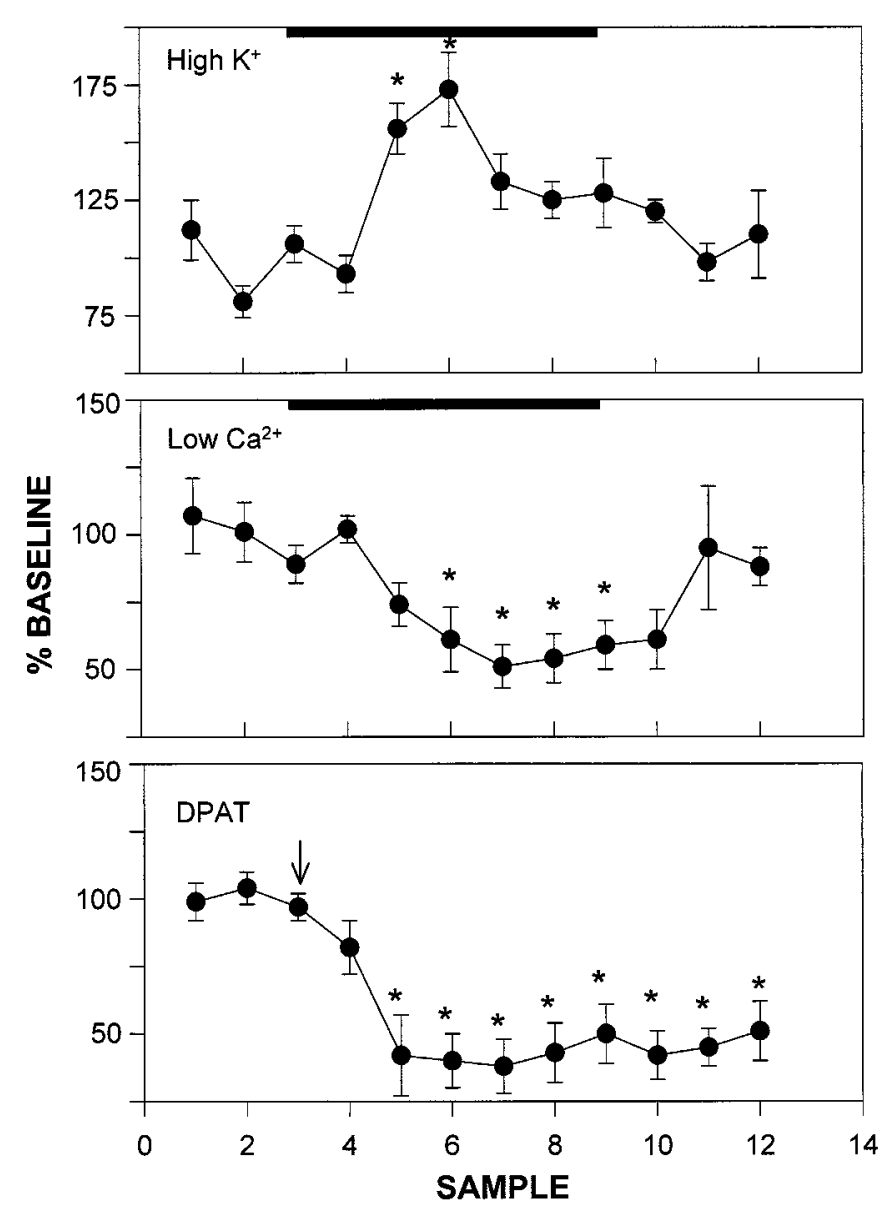

Figure 2. Pharmacologically induced changes in SCN microdialysate 5-HT concentrations. Top, Middle, Effects of localized perfusions with ACSF solutions containing high $\left[\mathrm{K}^{+}\right]$or no $\mathrm{Ca}^{2+}$, respectively, on 5-HT output. Solid bars denote the $2 \mathrm{hr}$ duration of the treatments. Bottom, Effect of intraperitoneal injection of 8-OH-DPAT on 5-HT output. Arrow designates the time of injection. The sample interval was $20 \mathrm{~min}$ for all treatments; $n=4-5$ for each experiment; ${ }^{*} p<0.05$ compared with pretreatment levels.

\section{RESULTS}

\section{Neuronal release of 5-HT from the SCN}

The chromatographed peak corresponding to authentic 5-HT standards was increased $73 \pm 16 \%$ over baseline by perfusion of the SCN with $100 \mathrm{~mm} \mathrm{KCl} \mathrm{(} p<0.05$; Fig. 2) and was decreased $50 \pm 10 \%$ by perfusion with $\mathrm{Ca}^{2+}$-free ACSF containing EDTA $(p<0.05)$. This peak was also decreased $62 \pm 10 \%$ by intraperitoneal injection of 8-OH-DPAT $(p<0.05)$ or $22 \pm 9 \%$ by intraperitoneal injection of BMY 7378 (daytime injection; $p<$ 0.05; see Fig. 10). Basal peak height also was increased $\sim 50$-fold by localized perfusion with citalopram (see Fig. 9).

\section{Daily profiles of 5-HT release in the SCN}

\section{Release under $L D$}

Twenty-four hour profile. The output of 5-HT measured from animals with probes located in the midposterior aspect of the SCN exhibited a diurnal fluctuation, with the nadir (83 $\pm 7 \%$ of the daily mean) occurring 2-3 hr before lights off and peak output (133 $\pm 13 \%$ of the daily mean) beginning at the time of lights off, constituting a $50 \%$ increase from the nadir $(p<0.05$; Fig. 3$)$. Output of 5-HT decreased to basal levels throughout the remain- der of the night. To verify that the $24 \mathrm{hr}$ profile of 5-HT assessed using microdialysis is of SCN origin, an experiment was undertaken using microdialysis probes with the dialysis tip occluded with epoxy, except for a small window of active membrane $(\sim 200 \times 300 \mu \mathrm{m})$ aimed medially at the $\operatorname{SCN}(n=3$ animals $)$. The $24 \mathrm{hr}$ release profile of 5-HT measured with these probes was equivalent to that assessed using the conventional probes (data not shown).

\section{Forty-eight hour profile}

Microdialysis performed in a separate group of animals $(n=5)$ continuously over $48 \mathrm{hr}$ confirmed the repetitive nature of the daily rhythm in 5-HT output in the SCN (Fig. 4). Although the rhythm symmetry was somewhat less regular than in the $24 \mathrm{hr}$ sampling group, significant nocturnal increases in 5-HT output over both LD cycles nevertheless began within $2 \mathrm{hr}$ of lights off. There was little diminution of microdialysate 5-HT concentration during the second day of sampling.

\section{Release Under DD}

The majority of hamsters maintained under DD for $\geq 2$ weeks exhibited a stable free-running rhythm of general locomotor activity before and during the microdialysis procedure. Similar to the profile of 5-HT release observed under $\mathrm{LD}$, a rise in 5-HT output occurred within $1 \mathrm{hr}$ after the onset of subjective night (CT 12; Fig. 5). The peak 5-HT output (165 $\pm 61 \%$ of the subjective daily mean) constituted an $\sim 83 \%$ increase over the nadir. Under both LD and DD conditions, 5-HT output averaged for the subjective night was significantly elevated over daytime levels (Fig. 6).

\section{Wheel-running-induced 5-HT release from the SCN}

Novelty-induced wheel-running during the day produced a significant increase in 5-HT output (Figs. 7, 8). The most robust stimulation was observed at ZT 4 ( $5 \mathrm{hr}$ after lights on), in which wheel-running induced an averaged maximal $52.3 \pm 17 \%$ increase in 5-HT output ( $p<0.05$ vs baseline). Wheel-running during the dark phase starting at ZT 19 (7 hr after lights off) caused a maximal $16.4 \pm 4 \%$ suppression in the mean level of 5-HT release over the running session $(p<0.05$ vs baseline; Fig. 7). This was not attributable to less active running, as the mean number of revolutions was twofold greater than that at ZT 4 ( $p<$ $0.01)$. Moreover, the lack of a stimulatory effect of running on 5-HT output at ZT 19-22 was not attributable to decreasing 5-HT baseline release, because there was no significant change in baseline output over this period. The proportionate degree of maximal increase in wheel-running-induced 5-HT release at $\mathrm{ZT}$ 4 measured in the presence of citalopram in the ACSF approximated that measured in the absence of citalopram (Fig. 9).

\section{Effect of BMY 7378 on 5-HT release from the SCN}

Hamsters that were treated with the mixed 5- $\mathrm{HT}_{1 \mathrm{~A}}$ autoreceptor agonist BMY 7378 at ZT 6 exhibited a $22 \pm 9 \%$ suppression of 5-HT output ( $p<0.05$ vs baseline; Fig. 10). In contrast, hamsters receiving the same dose of this drug at ZT 19 exhibited approximately a two times greater suppression of 5-HT output (46 \pm $7 \% ; p<0.05$ vs ZT 6).

\section{DISCUSSION}

By direct assessment of in vivo neuronal 5-HT output, we confirm a daily rhythm of neuronal 5-HT output in the Syrian hamster SCN. In animals entrained to a daily LD cycle, this rhythm was characterized by an abrupt increase in extracellular 5-HT from 
Figure 3. Daily profile of 5-HT release in the SCN region in hamsters maintained under 14/10 hr light/dark cycle. Solid bar denotes the dark phase. Each point represents the mean \pm SEM for 12 animals. ${ }^{*} p<0.05$ versus mean light phase level.
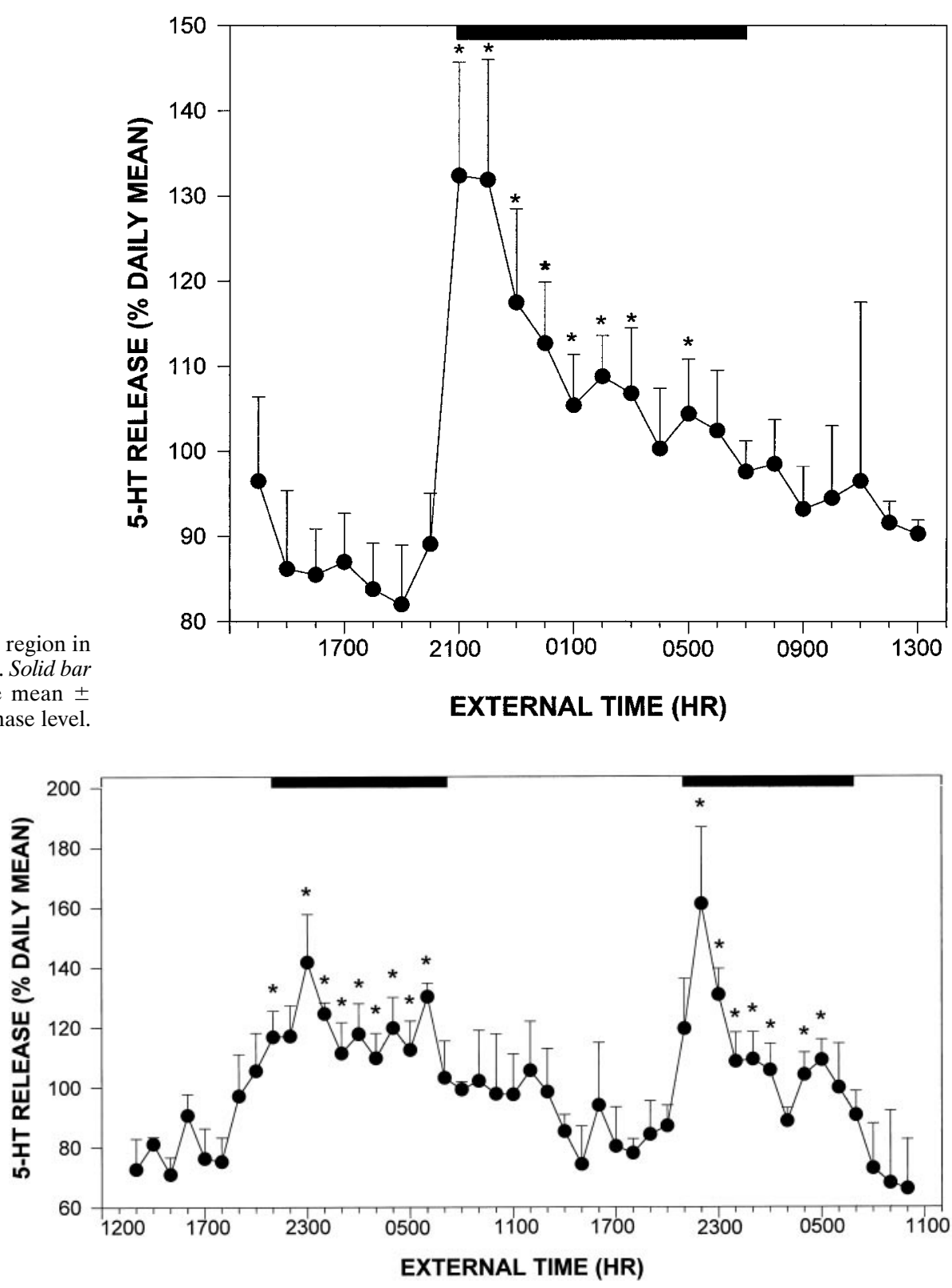

Figure 4. Daily profile of 5-HT release in the SCN region assessed over two consecutive 14/10 hr light/dark cycles. Solid bars denote the dark phase. Each point represents the mean \pm SEM for 5 animals. ${ }^{*} p<0.05$ versus mean light-phase level. low daytime levels to peak levels at the light/dark transition. This increase was temporally associated with active waking behaviors, and in most of the animals, output of 5-HT subsequently declined to basal levels during the remainder of the night. This pattern of 5-HT output is similar to that of 5-HIAA release reported previously in the SCN of this species (Glass et al., 1993), the rat (Faradji et al., 1983; Ramirez et al., 1987), and the Siberian hamster (Glass et al., 1992), in which increases in 5-HIAA output were also associated with the light/dark transition. Our data thus support the historical view that the increased extracellular concentration of 5-HIAA associated with lights off reflects increased neuronal 5-HT release. It is of note that an enhancement of 5-HT release at the light/dark transition has also been reported in rat cerebellum (Mendlin et al., 1996), hippocampus, striatum, amygdala, and frontal cortex using microdialysis (Rueter and Jacobs, 1996). A nocturnal increase in 5-HT release in the ventromedial hypothalamus also has been observed (Martin and Marsden, 1985). Thus, the nighttime activation of 5-HT output could be a widespread signal throughout the brain of nocturnal mammals serving to regulate multiple functions, including those of the circadian system.

Our demonstration that the 5-HT rhythm persists in freerunning hamsters maintained under long-term DD conditions strongly suggests that this rhythm is generated by an endogenous mechanism and is circadian in nature. This finding is consistent with observations of a daily rhythm in SCN tissue content of 5-HT that persists under DD, albeit out of phase with variations observed under LD (Cagampang and Inouye, 1994). It should be noted that these results differ from those of an earlier study, in which tissue 5-HT content in gross dissections of mediobasal and anterior regions of the hypothalamus displayed diurnal variations under LD but not under DD or constant light (Ferraro and Steger, 1990). However, because the contribution of 5-HT from the SCN per se cannot be assessed from such dissections, and the daily profile of 5-HT metabolism in the $\mathrm{SCN}$ is different from that in adjacent regions of the hypothalamus (Glass et al., 1992), it is 


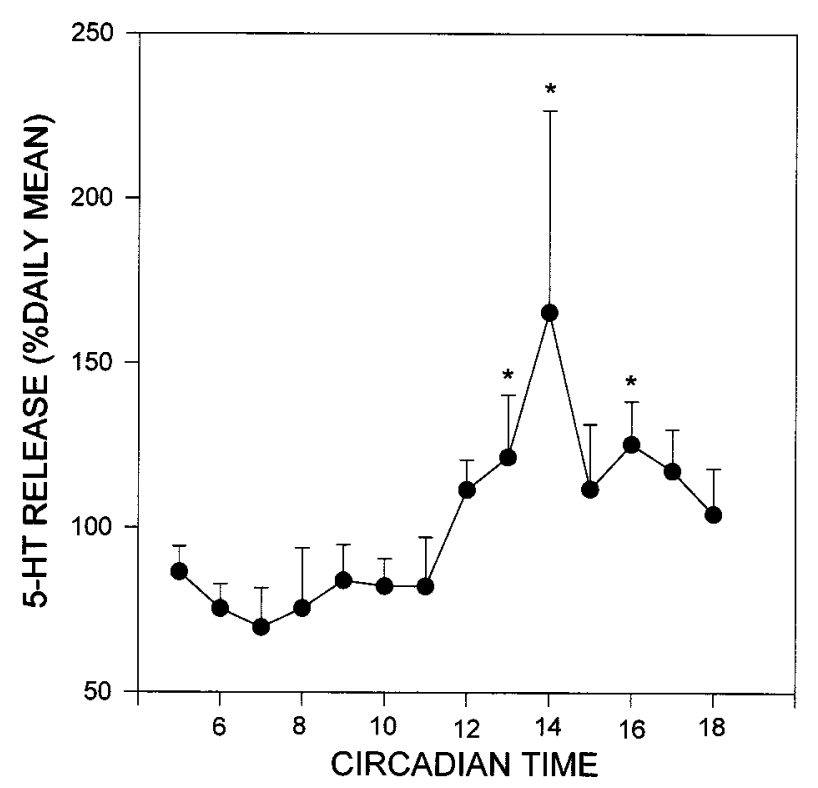

Figure 5. Daily profile of 5-HT release from the SCN region in hamsters maintained under constant dark (DD) for a minimum of 2 weeks. CT 12 represents the onset of subjective night as assessed by actograms. Each point represents the mean \pm SEM for 6 animals. ${ }^{*} p<0.05$ versus mean subjective day level.

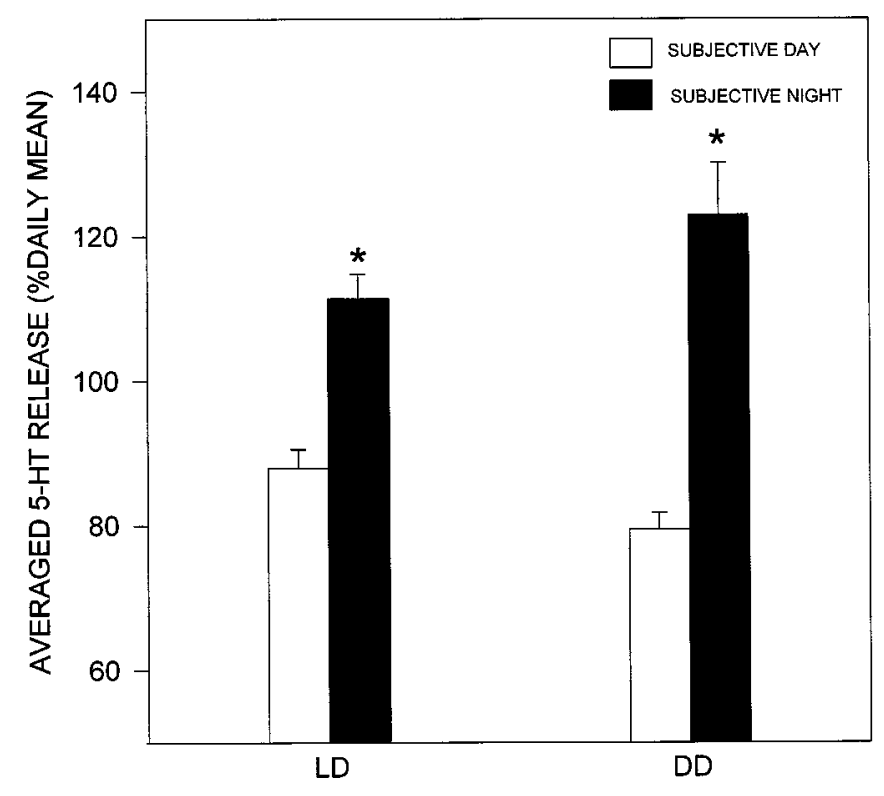

Figure 6. Averaged release of 5-HT in the SCN under LD $(n=12)$ and DD $(n=6)$. In both conditions, overall release of 5-HT is enhanced during subjective night. ${ }^{*} p<0.01$ versus respective subjective day.

not feasible to draw conclusions regarding SCN serotonergic activity from this approach. In the present study, the rise in SCN 5-HT output exhibited under DD began at the onset of the subjective night (the beginning of the active period), suggesting that the circadian activity rhythm could be an important determinant of the daily rhythm of 5-HT output in the SCN. Additional evidence that photic cues do not drive the SCN 5-HT rhythm is that the rhythm persists in appropriate phase on release of hamsters from LD into constant light (J. D. Glass, unpublished observations).
The present demonstration that 5-HT output in the SCN was significantly increased by $\mathrm{KCl}$-induced depolarization and was decreased by depletion of extracellular $\mathrm{Ca}^{2+}$ indicates that the extracellular 5-HT measured in the SCN microdialysates is largely of synaptic origin. The degree of response achieved with these manipulations was similar to that reported in other brain regions using microdialysis (Mendlin et al., 1996). Additional confirmation of the synaptic origin of 5-HT in SCN microdialysate is that localized perfusion with the 5-HT reuptake blocker citalopram increased microdialysate 5-HT concentrations, and that intraperitoneal administration of the $5-\mathrm{HT}_{1 \mathrm{~A}}$ receptor agonist $8-\mathrm{OH}$-DPAT or the mixed $5-\mathrm{HT}_{1 \mathrm{~A}}$ autoreceptor agonist BMY 7378 decreased 5-HT output, presumably via the activation of somatodendritic 5- $\mathrm{HT}_{1 \mathrm{~A}}$ autoreceptors. As final proof, we have reported previously that the extracellular concentration of 5-HT in the SCN measured by microdialysis is increased by electrical stimulation of the raphe (Dudley and Glass, 1996).

An important methodological consideration in this and other related studies is that the apparent daily rhythms in the output of 5-HT and 5-HIAA measured in the SCN (generally assessed for periods of $\leq 24 \mathrm{hr}$ ) could be artifacts of the in vivo sampling procedures. It is therefore critical to confirm the persistence of the rhythm over two or more daily cycles. This was verified for 5-HT by our continuous microdialysis sampling over two consecutive LD cycles. Over both cycles, significant daily fluctuations in 5-HT output were observed, with nocturnal increases occurring $\leq 1 \mathrm{hr}$ after lights off, after nadirs at the mid to late light phase. Levels of 5-HT during the second day of sampling were similar to those of the first day, reflecting the viability of presynaptic serotonergic terminals at the probe site throughout the experiment.

Behavioral state is considered an important determinant of central serotonergic activity (Schwartz et al., 1989; Wilkinson et al., 1991; Linthorst et al., 1995; Mendlin et al., 1996; Rueter and Jacobs, 1996). In particular, neuronal 5-HT release has been strongly correlated with increased levels of arousal and locomotor activity, including alert waking and postural adjustments, as well as feeding. Thus, in view of the pronounced in vivo effects of pharmacological serotonergic agonists on SCN clock phase (Tominaga et al., 1992; Edgar et al., 1993; Bobrzynska et al., 1996a) and photic entrainment processes (Rea et al., 1994; Glass et al., 1995; Pickard et al., 1996), it is possible that these functions could be modulated by behaviorally induced changes in 5-HT release. As an initial approach to this question, we sought to determine how 5-HT output in the SCN is affected by induced locomotor activity. Our results demonstrate that wheel-running markedly increased 5-HT release in the SCN in a phase-dependent manner, confirming a direct link between behavior and serotonergic activity in the circadian clock. The running-induced output of 5-HT during midday was correlated with running intensity, because with one exception, the active runners had a higher rate of 5-HT output than less active runners. A similar relationship has been reported in rat cerebellum, in which increases in 5-HT release were correlated with the duration of alert active waking at the light/dark transition (Mendlin et al., 1996).

The phase-related differences in the effect of wheel-running on 5-HT output in the SCN provide a novel perspective into the relationship between behavioral state and the regulation of serotonergic activity. The suppression of 5-HT release induced by wheel-running during the late dark phase, in contrast to the stimulation of 5-HT seen at midday, points to a diurnal variation in 5-HT neuronal response to behavioral activation. The control of raphe activity involves somatodendritic $5-\mathrm{HT}_{1 \mathrm{~A}}$ autoreceptors 
Figure 7. Profiles of novel wheel-runninginduced alterations in 5-HT release from the $\mathrm{SCN}$ region during midday (ZT $4-7)$ and during the late dark phase (ZT 19-22). Solid bar denotes the $3 \mathrm{hr}$ period of confinement in the wheel. ${ }^{*} p<0.05$ relative to prerunning baseline. Data from all animals in each group are included irrespective of running intensity. Inset, Bars represent total number of revolutions over the $3 \mathrm{hr}$ wheel-running period for both groups. ${ }^{*} p<0.05$ between groups.

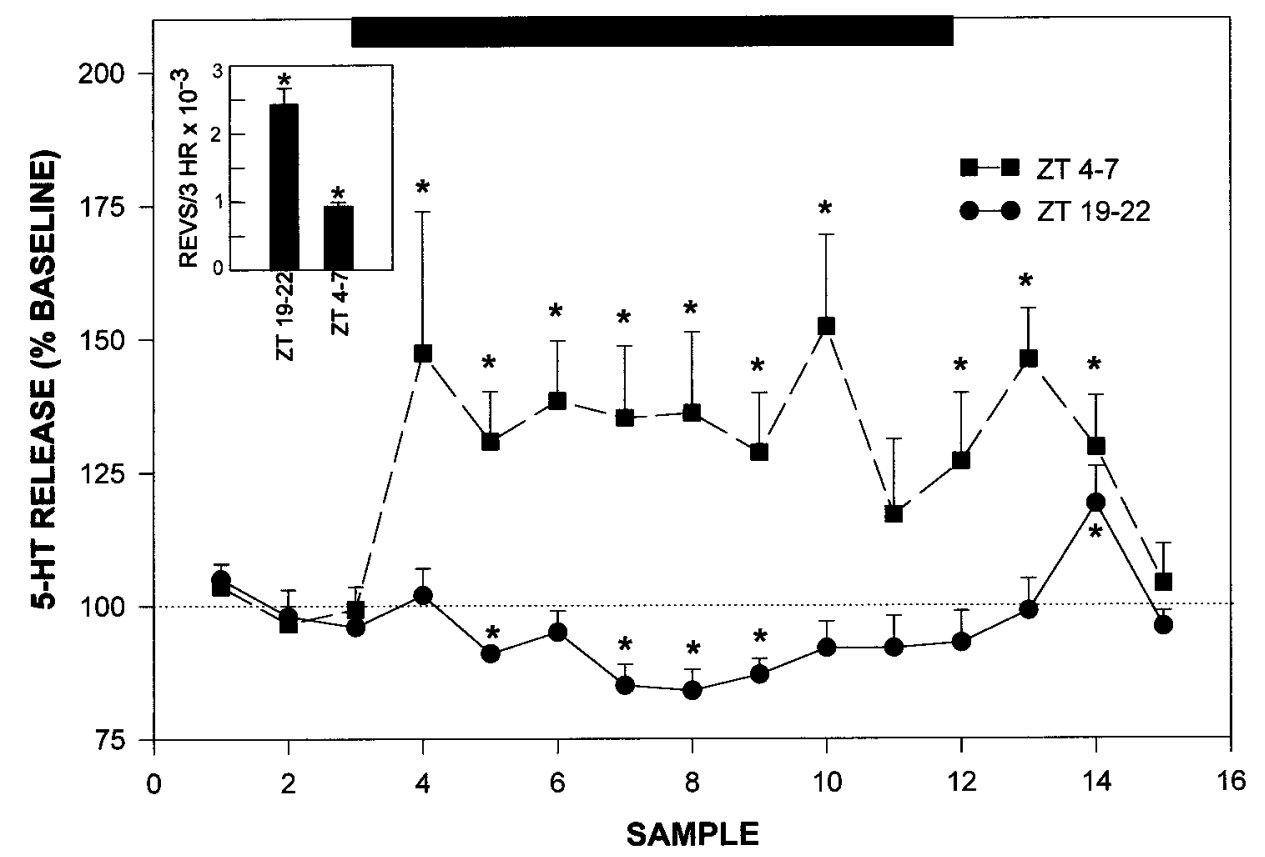

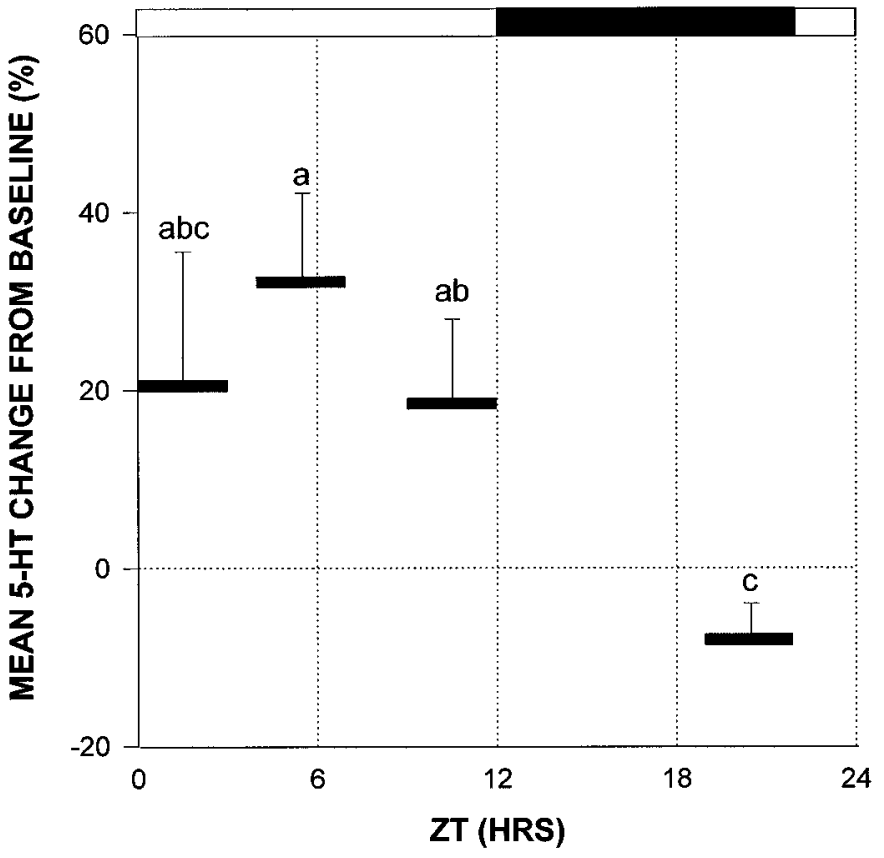

Figure 8. Time of day difference in the effect of novel wheel running on 5-HT release averaged over the entire $3 \mathrm{hr}$ running period from the SCN region. The vertical position and length of the solid bars denote the mean level of 5-HT release and period of wheel running, respectively. Data from all animals in each group are included irrespective of running intensity. Solid bar at the top denotes the dark phase. Groups with different letters are different from each other; $p<0.05$.

(Garrat et al., 1988; O'Connor and Kruk, 1992), and thus, a daily variation in $5-\mathrm{HT}_{1 \mathrm{~A}}$ autoreceptor-mediated response could underlie the biphasic time-of-day effect of wheel-running on 5-HT release in the SCN. We tested this possibility by examining the inhibitory effect of the mixed $5-\mathrm{HT}_{1 \mathrm{~A}}$ autoreceptor agonist BMY 7378 on SCN 5-HT release at the times of greatest difference in effect of wheel-running on 5-HT release. The substantially greater suppressive effect of BMY 7378 on 5-HT release at ZT 19,

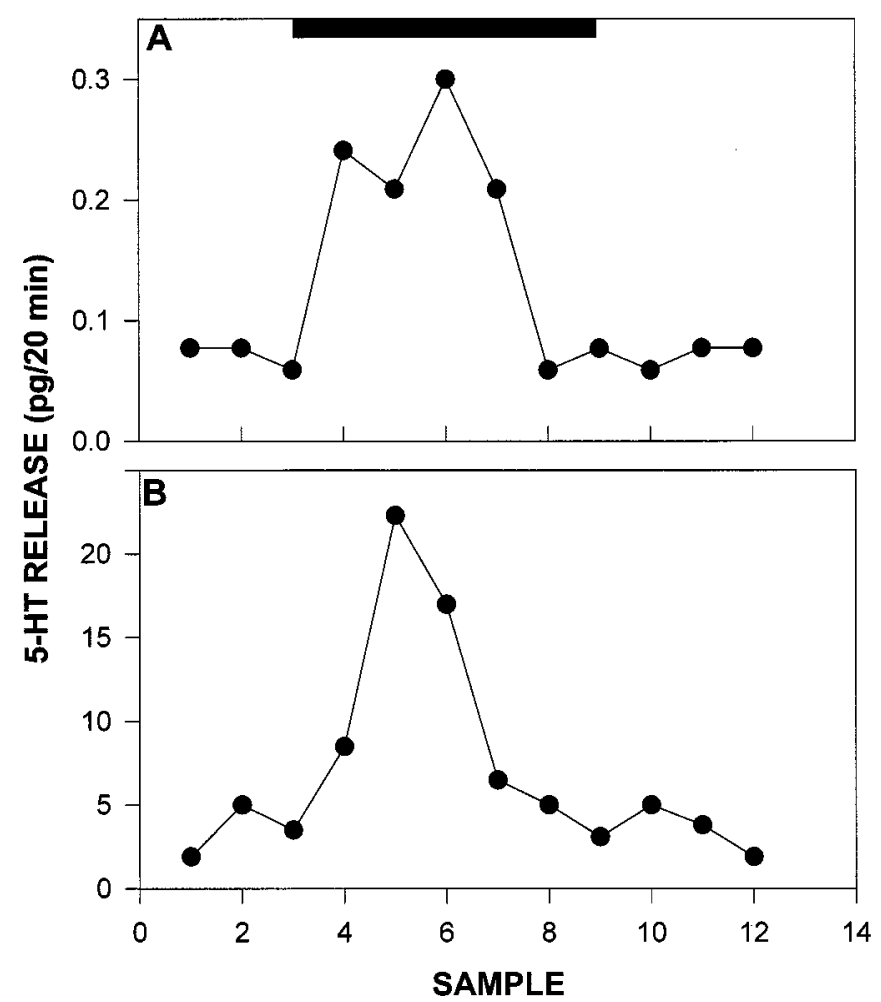

Figure 9. Individual profiles of 5-HT release from the SCN collected before, during, and after $2 \mathrm{hr}$ of novelty-induced wheel-running. Solid bar denotes the period of confinement in the wheel. $A, 5-\mathrm{HT}$ measured without reuptake blocker (citalopram) added to the ACSF. B, 5-HT measured with citalopram added to the ACSF. Note differences in vertical axis scales. Sample interval is $20 \mathrm{~min}$.

compared with ZT 6, is evidence for a daily variation in $5-\mathrm{HT}_{1 \mathrm{~A}}$ autoreceptor-mediated response. Previous evidence for a daily variation in raphe autoreceptor responsiveness is the observation of a biphasic feeding response of rats to intraraphe injections of the $5-\mathrm{HT}_{1 \mathrm{~A}}$ agonist 8-OH-DPAT with stimulation during mid to 


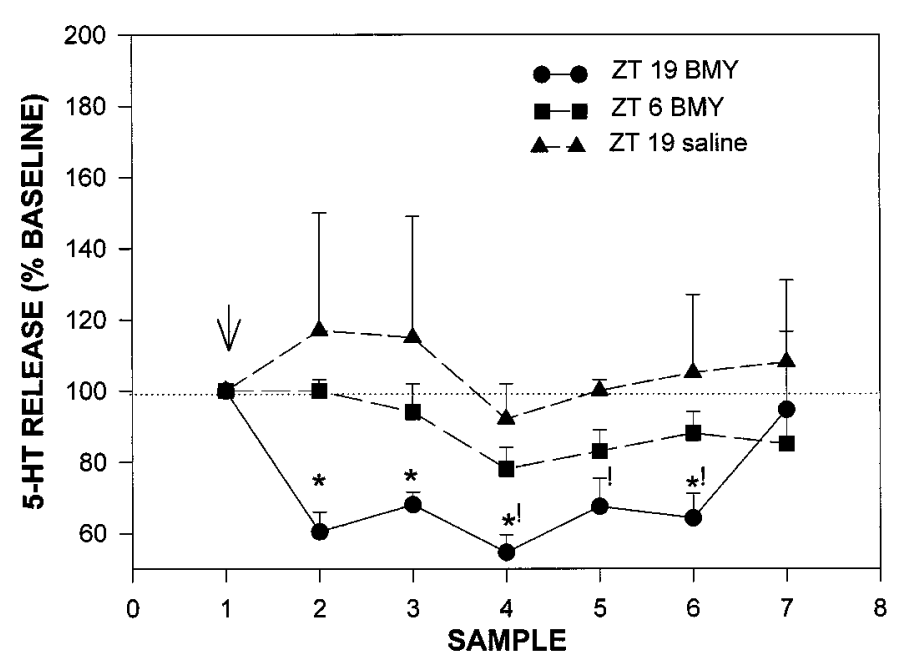

Figure 10. Time of day difference in the inhibitory effect of intraperitoneal injection of BMY 7378 on 5-HT release from the SCN region. Arrow denotes time of injection. Sampling interval is 20 min. ${ }^{*} p<0.05$ versus same time point at ZT 6; $p<0.05$ versus saline control.

late dark phase and inhibition soon after lights off (Currie and Coscina, 1993). There is also support for a diurnal variation in response of central $5-\mathrm{HT}_{1 \mathrm{~A}}$ postsynaptic receptors $(\mathrm{Lu}$ and $\mathrm{Na}-$ gayama, 1996). It is thus plausible that 5 -HT output in response to strenuous wheel-running at ZT 19-22 strongly inhibited raphe activity via enhanced $5-\mathrm{HT}_{1 \mathrm{~A}}$ autoreceptor activity during the late dark phase, thus preventing the sustained increase in 5-HT output exhibited by wheel runners during the day.

The present demonstration that appropriately timed wheel running can stimulate neuronal 5-HT release is further evidence that increased 5-HT output could mediate nonphotic phase shifting. Previous evidence for this is that behavioral activity induced by wheel running, cage changing (Mrosovsky et al., 1989; Reebs and Mrosovsky, 1989), or treatment with the $\mathrm{GABA}_{\mathrm{A}}$ agonist triazolam (Turek and Van Reeth, 1988; Tominaga et al., 1992; Penev et al., 1995) phase advances the circadian activity rhythm in a similar manner as that induced by $5-\mathrm{HT}_{1 \mathrm{~A}}$ agonists, with maximal shifting at approximately CT 6-8. Depletion of 5-HT in whole brain by intraperitoneal injection of $p$-chloroamphetamine (Penev et al., 1995) or in the SCN by microinjection of 5,7-DHT (Cutrera et al., 1994) or blockade of 5-HT action by the peripheral administration of $5-\mathrm{HT}_{7 / 2}$ receptor antagonists (Sumova et al., 1996) attenuates triazolam- or arousal-induced (latter study) phase advances. However, the recent report that depletion of 5-HT in the SCN by intra-SCN microinjection of 5,7-DHT does not block wheel-running-induced phase advances in hamsters (Bobrzynska et al., 1996a) suggests that the SCN may not be a target for the phase-shifting action of 5-HT. This is consistent with the observation that 8-OH-DPAT causes phase advances when microinjected into the raphe nuclei but not the SCN or intergeniculate leaflet (Mintz et al., 1997). Thus, it is unclear whether activity-induced increases in 5-HT may act directly on the SCN or may exert an indirect effect on the SCN via action at the raphe or other sites that influence SCN function. Further assessments will be required to establish the identity of the target(s) of 5-HT for the induction of nonphotic phase shifts.

In summary, the present findings confirm the existence of an endogenous circadian rhythm in neuronal 5-HT release in the $\mathrm{SCN}$ that can occur in the absence of photic cues. The findings that 5-HT output in the SCN can be increased by appropriately timed activity pulses and in association with active waking behaviors at the light/dark transition suggest that behavioral state could be an important determinant of the circadian pattern of 5-HT release in the circadian clock.

\section{REFERENCES}

Azmitia EC, Segal M (1978) An autoradiographic analysis of the differential ascending projections of the dorsal and median raphe nuclei in the rat. J Comp Neurol 179:641-660.

Banky Z, Molnar J, Csernus V, Halasz B (1988) Further studies on circadian hormone rhythms after local pharmacological destruction of the serotonergic innervation of the rat suprachiasmatic region before the onset of the corticosterone rhythm. Brain Res 445:222-227.

Biello SM, Janik D, Mrosovsky N (1994) Neuropeptide Y and behaviorally induced phase shifts. Neuroscience 62:273-279.

Bobrzynska KJ, Godfrey MH, Mrosovsky N (1996a) Serotonergic stimulation and nonphotic phase-shifting in hamsters. Physiol Behav 59:221-230.

Bobrzynska KJ, Vrang N, Mrosovsky N (1996b) Persistence of nonphotic phase shifts in hamsters after serotonin depletion in the suprachiasmatic nucleus. Brain Res 741:205-214.

Cagampang FRA, Inouye S-IT (1994) Diurnal and circadian changes of serotonin in the suprachiasmatic nuclei: regulation by light and an endogenous pacemaker. Brain Res 639:175-179.

Card JP, Moore RY (1982) Ventral lateral geniculate nucleus efferents to the rat suprachiasmatic nucleus exhibit avian pancreatic polypeptidelike immunoreactivity. J Comp Physiol 206:390-396.

Currie PJ, Coscina DV (1993) Diurnal variations in the feeding response to 8-OH-DPAT injected into the dorsal or median raphe. NeuroReport 4:1105-1107.

Cutrera RA, Kalsbeek A, Pevet P (1994) Specific destruction of the serotonergic afferents to the suprachiasmatic nuclei prevents triazolaminduced phase advances of hamster activity rhythms. Behav Brain Res 62:21-28.

Dudley T, Glass JD (1996) Endogenous 5-HT release in the Syrian hamster SCN. Proc Soc Res Biol Rhythms abstract 48.

Duncan WC, Tamarkin L, Sokolove PG, Wehr TA (1988) Chronic clorgyline treatment of Syrian hamsters: an analysis of effects of the circadian pacemaker. J Biol Rhythms 3:305-322.

Edgar DM, Miller JD, Prosser RA, Dean RR, Dement WC (1993) Serotonin and the mammalian circadian system: II. Phase-shifting rat behavioral rhythms with serotonergic agonists. J Biol Rhythms 8:17-31.

Faradji H, Cespuglio R, Jouvert M (1983) Voltametric measurements of 5-hydroxyindole compounds in the suprachiasmatic nuclei. Circadian fluctuations. Brain Res 279:111-119.

Ferraro JS, Steger RW (1990) Diurnal variations in brain serotonin are driven by the photic cycle and are not circadian in nature. Brain Res 512:121-124.

Garrat J, Marsden CA, Crespi F (1988) 8-OH-DPAT can decrease 5-HT neuronal firing and release but not metabolism. $\mathrm{Br} \mathrm{J}$ Pharmacol 95:874p.

Glass JD, Randolph WW, Ferreira SA, Rea MA, Hauser UE, Blank JL, De Vries MJ (1992) Diurnal variation in 5-hydroxyindoleacetic acid output in the suprachiasmatic region of the Siberian hamster assessed by in vivo microdialysis: evidence for nocturnal activation of serotonin release. Neuroendocrinology 56:582:590.

Glass JD, Hauser UE, Blank JL, Selim M, Rea MA (1993) Differential timing of amino acid and 5-HIAA rhythms in suprachiasmatic hypothalamus. Am J Physiol 265:R504-R511.

Glass JD, Selim M, Rea MA (1994) Modulation of light-induced c-fos expression in the suprachiasmatic nuclei by 5 -HT receptor agonists. Brain Res 638:235-242.

Glass JD, Selim M, Srkalovic G, Rea MA (1995) Tryptophan loading modulates light-induced responses in the mammalian circadian system. J Biol Rhythms 10:80-90.

Hendrickson AE, Wagoner N, Cowan WM (1972) An autoradiographic and electron microscope study of retinohypothalamic connections. Z Zellforsch Mikrosk Anat 135:1-26.

Hery M, Faudon M, Dusticier G, Hery F (1982) Daily variations in serotonin metabolism in the suprachiasmatic nucleus of the rat: influence of oestradiol impregnation. J Endocrinol 94:157-166.

Honma KI, Watanabe K, Hiroshige T (1979) Effects of parachlorophenylalanine and 5,6-dihydroxytryptamine on the free-running rhythms of 
locomotor activity and plasma corticosterone in the rat exposed to constant light. Brain Res 169:531-544.

Janik D, Mrosovsky N (1994) Intergeniculate lesions and behaviorallyinduced shifts of circadian rhythms. Brain Res 651:174-182.

Janik D, Mikkelsen JD, Mrosovsky N (1995) Cellular colocalization of fos and neuropeptide $\mathrm{Y}$ in the intergeniculate leaflet after nonphotic phase-shifting events. Brain Res 698:137-145.

Johnson RF, Morin LP, Moore RY (1988) Retinohypothalamic projections in the hamster and rat demonstrated using cholera toxin. Brain Res 462:301-312.

Johnson RF, Moore RY, Morin LP (1989) Lateral geniculate lesions alter circadian activity rhythms in the hamster. Brain Res Bull 22:411-422.

Klein DC, Moore RM, Reppert SM (1991) Suprachiasmatic nucleus: the mind's clock. New York: Oxford UP.

Levine JD, Rosenwasser AM, Yanovski JA, Adler NT (1986) Circadian activity rhythms in rats with midbrain raphe lesions. Brain Res 384:240-249.

Linthorst ACE, Flachskamm C, Muller-Preuss P, Holsboer F, Reul JMHM (1995) Effect of bacterial endotoxin and interleukin-1 $\beta$ on hippocampal serotonergic neurotransmission, behavioral activity and free corticosterone levels: an in vivo microdialysis study. J Neurosci 15:2920-2934.

Lu J-Q, Nagayama H (1996) Circadian rhythm in the response of central $5-\mathrm{HT}_{1 \mathrm{~A}}$ receptors to $8-\mathrm{OH}-\mathrm{DPAT}$ in rats. Psychopharmacology 123:42-45.

Martin KF, Marsden CA (1985) In vivo diurnal variations of 5-HT release in hypothalamic nuclei. In: Circadian rhythms in the CNS (Redfern PH, Campbell IC, Davies JA, Martin KF, eds), pp 81-94. London: Macmillan.

Mason R (1986) Circadian variation in sensitivity of suprachiasmatic and lateral geniculate neurones to 5-hydroxytryptamine in the rat. J Physiol (Lond) 377:1-13.

Medanic M, Gillette MU (1992) Serotonin regulates the phase of the rat suprachiasmatic circadian pacemaker in vitro only during the subjective day. J Physiol (Lond) 450:629-642.

Mendlin A, Martin FJ, Rueter LE, Jacobs BL (1996) Neuronal release of serotonin in the cerebellum of behaving rats: an in vivo microdialysis study. J Neurochem 67:617-622.

Meyer DC, Quay WB (1976) Hypothalamic and suprachiasmatic uptake of serotonin in vitro: $24 \mathrm{hr}$ changes in male and proestrous female rats. Endocrinology 98:1160-1165.

Meyer-Bernstein EL, Morin LP (1996) Differential serotonergic innervation of the suprachiasmatic nucleus and the intergeniculate leaflet and its role in circadian rhythm modulation. J Neurosci 16:2097-2111.

Miller JD, Fuller CA (1990) The response of suprachiasmatic neurons of the rat hypothalamus to photic and serotonergic stimulation. Brain Res 515:155-162.

Mintz EM, Gillespie CF, Marvel CL, Huhman KL, Albers HE (1997) Serotonergic regulation of circadian rhythms in Syrian hamsters. Neuroscience 79:563-569.

Moore RY (1983) Organization and function of a CNS oscillator: the suprachiasmatic nucleus. Fed Proc 42:2783-2789.

Moore RY, Lenn NJ (1972) A retinohypothalamic projection in the rat. J Comp Neurol 146:1-14.

Moore RY, Halaris AE, Jones BE (1978) Serotonin neurons of the midbrain raphe: ascending projections. J Comp Neurol 180:417-438.

Morin LP, Blanchard J (1991a) Depletion of brain serotonin by 5,7DHT modifies hamster circadian rhythm response to light. Brain Res 566:173-185.

Morin LP, Blanchard J (1991b) Serotonergic modulation of the hamster wheel-running rhythm: response to lighting conditions and food deprivation. Brain Res 566:186-192.

Mrosovsky N, Reebs SG, Honrada GI, Salmon PA (1989) Behavioral entrainment of circadian rhythms. Experientia 45:696-702.

O'Connor JJ, Kruk ZL (1992) Pharmacological characteristics of 5-hydroxytryptamine autoreceptors in rat brain slices incorporating the dorsal raphe or the suprachiasmatic nucleus. $\mathrm{Br} \mathrm{J}$ Pharmacol 106:524-532.

Penev PD, Turek FW, Zee PC (1995) A serotonin neurotoxin attenuates the phase-shifting effects of triazolam on the circadian clock in hamsters. Brain Res 669:207-216.

Pickard GE (1982) The afferent connection of the suprachiasmatic nu- cleus of the golden hamster with emphasis on retinohypothalamic projection. J Comp Neurol 211:65-83.

Pickard GE, Weber ET, Scott PA, Riberdy AF, Rea MA (1996) $5 \mathrm{HT}_{1 \mathrm{~B}}$ receptor agonists inhibit light-induced phase shifts of behavioral circadian rhythms and expression of the immediate-early gene c-fos in the suprachiasmatic nucleus. J Neurosci 16:8208-8220.

Prosser RA, Miller JD, Heller HC (1990) A serotonin agonist phaseshifts the circadian clock in the suprachiasmatic nuclei in vitro. Brain Res 534:336-339.

Prosser RA, Dean RR, Heller HC, Miller JD (1993) Serotonin and the mammalian circadian system: I. In vitro phase-shifts by serotonergic agonists and antagonists. J Biol Rhythms 8:1-16.

Ramirez AD, Ramirez VD, Meyer DC (1987) The nature and magnitude of in vivo 5-hydroxyindoleacetic acid output from 5-hydroxytryptamine terminals is related to specific regions of the the suprachiasmatic nucleus. Neuroendocrinology 46:430-438.

Rea MA, Glass JD, Colwell CS (1994) Serotonin modulates photic responses on the hamster suprachiasmatic nuclei. J Neurosci $14: 3635-3642$.

Reebs SG, Mrosovsky N (1989) Effects of induced wheel-running on the circadian activity rhythm of Syrian hamsters: entrainment and phaseresponse curve. J Biol Rhythms 4:39-48.

Rueter LE, Jacobs BL (1996) Changes in forebrain serotonin at the light-dark transition: correlation with behavior. NeuroReport 7:1107-1111.

Rusak B, Zucker I (1979) Neural regulation of circadian rhythms. Physiol Rev 59:449-526.

Rusak B, Meijer JH, Harrington ME (1989) Hamster circadian rhythms are phase-shifted by electrical stimulation of the geniculo-hypothalamic tract. Brain Res 493:283-291.

Schwartz DH, McClane S, Hernandez L, Hoebel BG (1989) Feeding increases extracellular serotonin in the lateral hypothalamus of the rat as measured by microdialysis. Brain Res 479:349-354.

Selim M, Glass JD, Hauser UE, Rea MA (1993) Serotonergic inhibition of light-induced fos protein expression and extracellular glutamate in the suprachiasmatic nuclei. Brain Res 621:181-188.

Shibata S, Tsuneyoshi A, Hamada T, Tominaga K, Watanabe S (1992) Phase-resetting effect of 8-OH-DPAT, a serotonin ${ }_{1 \mathrm{~A}}$ receptor agonist, on the circadian rhythm of firing rate in the rat suprachiasmatic nuclei in vitro. Brain Res 582:353-356.

Smale L, Michels KM, Moore RY, Morin LP (1990) Destruction of the hamster serotonergic system by 5,7-DHT: effects on circadian rhythm phase, entrainment and response to triazolam. Brain Res 515:9-19.

Sumova A, Maywood ES, Selvage D, Ebling FJP, Hastings MH (1996) Serotonergic antagonists impair arousal-induced phase shifts of the circadian system of the Syrian hamster. Brain Res 709:88-96.

Szafarczyk A, Ixart G, Alonso G, Malaval F, Nouglier-Soule J, Assenmacher I (1981) Effects of raphe lesions on circadian ACTH, corticosterone and motor activity rhythms in free-running blinded rats. Neurosci Lett 23:92-97.

Tominaga K, Shibata S, Ueki S, Watanabe S (1992) Effects of 5-HT receptor agonists on the circadian rhythm of wheel-running activity in hamsters Eur J Pharmacol 214:79-84.

Turek FW, Van Reeth O (1988) Altering the mammalian circadian clock with the short-acting benzodiazepine, triazolam. Trends Neurosci 11:535-541.

Wilkinson LO, Auerbach SB, Jacobs BL (1991) Extracellular serotonin levels change with behavioral state but not with pyrogen-induced hyperthermia. J Neurosci 11:2732-2741.

Ying S-W, Rusak B (1994) Effects of serotonergic agonists on firing rates of photically responsive cells in the hamster suprachiasmatic nucleus. Brain Res 651:37-46.

Ying S-W, Rusak B (1997) 5- $\mathrm{HT}_{7}$ receptors mediate serotonergic effects on light-sensitive suprachiasmatic nucleus neurons. Brain Res 755:246-254.

Youngstrom TG, Nunez AA (1986) Comparative anatomy of the retinohypothalamic tract in photoperiodic and nonphotoperiodic rodents. Brain Res Bull 17:485-492.

Wirz-Justice A, Krauchi K, Morimasa T, Willener R, Feer H (1983) Circadian rhythm of $\left({ }^{3} \mathrm{H}\right)$ imipramine binding in the rat suprachiasmatic nucleus. Eur J Pharmacol 87:331-333.

Zar JH (1983) Biostatistical analysis. Englewood Cliffs, NJ: PrenticeHall. 